\title{
Peer learning leaders: developing employability through facilitating the learning of other students
}

\author{
Neil Ford \\ Bournemouth University, UK \\ Charlotte Thackeray \\ Bournemouth University, UK \\ Paul Barnes \\ Bournemouth University, UK \\ Katharina Hendrickx \\ Bournemouth University, UK
}

\section{Abstract}

Employability is a key theme in higher education and attitudes towards its development have shifted from a focus on technical skills development to a broader focus on values, intellect, social engagement and performance contributing to graduate identity (Hager and Hodkinson, 2009). Peer Assisted Learning (PAL) and Language Conversation Clubs are both examples of student-led peer learning schemes at Bournemouth University (BU), and are reviewed to explore the development of students employed to lead and facilitate group learning sessions. Data from four annual evaluation surveys $(n=239)$ is reviewed in addition to qualitative comments and reflective writing. Peer leaders were found to have developed employability attributes including: leadership, time management and organisation, communication, and cultural awareness. Above all, peer leaders identified with developing confidence in their roles. Comments provided examples of student leaders who had actively selected peer learning as an opportunity to develop their confidence and were able to transfer this to other academic and employment contexts.

Keywords: Peer Assisted Learning; PAL; employability; graduate attributes; graduate identity; confidence. 


\section{Background context}

Employability is a key theme in contemporary higher education as we prepare graduates to participate in an increasingly global society (Higher Education Academy, 2014; Higher Education Academy, 2015). Currently, the HEA defines employability as:

A set of achievements - skills, understandings and personal attributes - that makes graduates more likely to gain employment and be successful in their chosen occupations. (Pegg et al., 2012, p.4)

Early work to develop employability in higher education tended to focus on teaching practical or technical skills that graduates of a particular discipline were expected to demonstrate (for example IT skills). More recent definitions of employability recognise the importance of higher critical and metacognitive attributes, such as critical thinking (reflection), communication and cultural awareness (Harvey, 2003), that enable graduates to adapt to the organisational culture and apply their skills to shape innovation and change (Lowden et al., 2011). In this model, graduate employability comprises a range of:

Inter-related attributes, skills and competencies that help individuals to both secure and perform well in employment. (Lowden et al., 2011, p.4).

Contemporary approaches to developing employability accordingly focus on providing opportunities for students to develop a graduate identity comprised of values, intellect, social engagement and performance (Hinchliffe and Jolly, 2011; Hager and Hodkinson, 2009).

The employment landscape is increasingly diverse, global and environmentally aware (Hinchliffe and Jolly, 2011, p.574) and industry reports a skills gap of the personal attributes needed to thrive in this environment. Attributes such as communication, leadership and creative problem-solving are highly prized, but employers observe that graduates are unlikely to have developed them (Bloomberg Business, 2015).

There is increasing recognition that developing employability is an active, experiential process, requiring a departure from didactic pedagogies to more active, social and reflective forms of learning: 
The ability to articulate learning and raising confidence, self-esteem and aspirations seem to be more significant in developing graduates than a narrow focus on skills and competencies. (Pegg et al., 2012, p.9)

In summary, attitudes towards employability have shifted from a skills-based focus to an emphasis on transferable attributes, values and experiences (for example, communication, leadership, confidence and diversity). Current understanding is that, as well as learning skills and developing attributes, students need authentic experiences to apply their learning, as well as opportunities to assess their progress and identify future development needs (Deeley, 2014).

\section{Two forms of peer learning at BU}

This paper explores how two forms of peer learning at Bournemouth University (BU) Peer Assisted Learning (PAL) and Language Conversation Clubs - contribute to the development of employability in the student leaders trained to facilitate sessions.

It should be noted that, whilst there is a wealth of anecdotal evidence, and several papers identify potential employability benefits for peer leaders (Stout and McDaniel, 2006; Saunders and Gibbon, 1998; Capstick, 2004), there is a lack of hard evidence in the literature (Dawson et al., 2014). Many institutions who practice peer learning schemes have observed that the peer leaders gain more than the students who participate (Donelan 1999, cited Stout and McDaniel, 2006), however, much of the evidence for this is anecdotal.

Whilst this paper does not present any research specifically undertaken to investigate a causal link between peer learning and employability, we are able to offer observations from our schemes that strongly support a link and hope that this leads to further research and discussion.

\section{Peer Assisted Learning (PAL)}

Peer Assisted Learning (PAL) was formally established at BU in 2001. Although it has evolved some distinct features to meet local needs, it retains links to the University of 
Missouri-Kansas City, Supplemental Instruction (SI) model: for example, all current trainers of PAL Leaders have attended supervisor training provided by the PASS (Peer Assisted Study Sessions) National Centre.

PAL provides active, group-learning facilitated by more experienced students who have been trained to help students to adjust to independent learning and develop understanding of their course (Bournemouth University, 2014). It runs across all full-time undergraduate courses at BU and currently employs approximately 300 students as PAL Leaders.

As well as supporting the learning of participants, PAL offers significant development opportunities for the PAL Leaders. Annual surveys of PAL Leaders evaluate how they feel they have developed through their experiences of regularly facilitating group learning.

\section{Conversation Clubs for independent language learners}

The independent language learning scheme at BU is open to all students and staff wanting to learn a new language or improve their existing knowledge. It promotes the advantages of independent language learning whilst also addressing disadvantages: namely a lack of opportunity to actively use the language with other students who have similar cultural interests.

To address this disadvantage, Conversation Clubs were introduced for French, German and Spanish in 2005. Originally, these were only available to intermediate or advanced learners, and were soon extended to include the majority of independent language learners who are beginners or false beginners.

The language portfolio has since expanded to include Italian, Mandarin Chinese and Arabic, and Conversation Clubs now employ 15 international students who are native speakers to facilitate these clubs. Training, resources and registers are provided for the facilitators who organise the clubs themselves in collaboration with the learners. They decide on the times of the clubs and also book the rooms they require.

English Conversation and Culture Clubs have also been added to provide international students with an informal environment to improve their speaking and listening skills, and to find out more about British culture. International students from some cultures, who may be 
reluctant to participate in academic seminars, may participate in a session led by fellow students to improve their speaking confidence and enable greater engagement in seminars.

\section{Methods}

A range of data from PAL and Conversation Clubs was analysed to provide insight into student leaders' employability development. Implications are discussed below and include the following sources of data:

\section{1) PAL Surveys}

PAL Leaders are surveyed annually, including a question that asks them to tick to indicate: 'Which of these skills(s) did you develop during your experience being a PAL Leader? Organisation/presentation skills; Listening/communication skills; Leadership/teamwork skills; Confidence; Problem solving/'thinking on my feet'; Other (please specify)' (Ford and Thackeray, 2014). We aggregated the last four years' results to give an indication of the employability attributes that PAL Leaders commonly associated with their role (see Table 1).

Table 1 - Summary of PAL Leader survey results relating to employability attributes

\begin{tabular}{|c|c|c|c|c|c|c|}
\hline & & 2011/12 & $2012 / 13$ & $2013 / 14$ & 2014/15 & Total \\
\hline \multirow{3}{*}{ 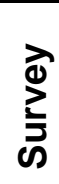 } & Number of Responses & 60 & 36 & 75 & 68 & 239 \\
\hline & Total PAL Leaders & 146 & 170 & 260 & 253 & 829 \\
\hline & \% Response Rate & 41.1 & 21.2 & 28.9 & 26.9 & 28.8 \\
\hline \multirow{6}{*}{ 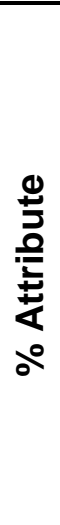 } & $\begin{array}{l}\text { Problem solving/'thinking on } \\
\text { my feet' }\end{array}$ & $71.7 \%$ & $66.7 \%$ & $74.7 \%$ & $67.6 \%$ & $70.7 \%$ \\
\hline & Confidence & $95 \%$ & $80.6 \%$ & $82.7 \%$ & $77.9 \%$ & $84.1 \%$ \\
\hline & Leadership/teamwork skills & $83.3 \%$ & $69.4 \%$ & $74.7 \%$ & $77.9 \%$ & $77 \%$ \\
\hline & $\begin{array}{l}\text { Listening/communication } \\
\text { skills }\end{array}$ & $73.3 \%$ & $75 \%$ & $85.3 \%$ & $77.9 \%$ & $78.7 \%$ \\
\hline & Organisation/presentation & & & & & \\
\hline & skills & $75 \%$ & $80.6 \%$ & $88 \%$ & $80.9 \%$ & $81.6 \%$ \\
\hline
\end{tabular}


The proportion of PAL Leaders recognising each attribute is fairly consistent. Figure 1 shows the aggregate percentages across the whole period.

Figure 1. \% PAL Leaders recognising the development of employability attributes (2011/12 to 2014/15).

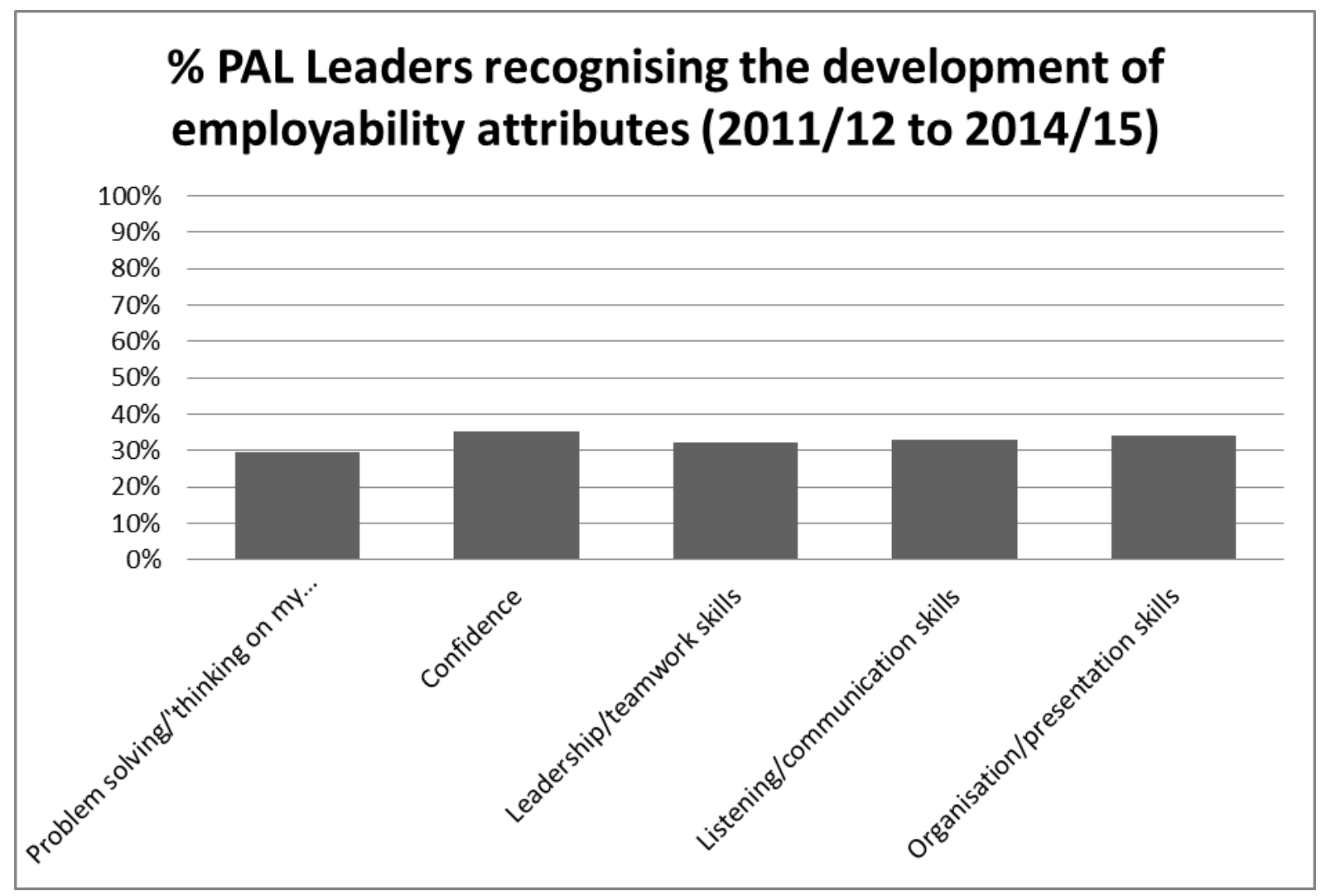

During June 2015, a short, informal, follow-up survey was delivered to all PAL Leaders who are current students (past three years) asking them to pick the attribute that PAL had most helped them to develop and then provide a response to the question 'How did being a PAL Leader help you to develop this attribute?'. 56 responses were received (representing a response rate of $8.2 \%$ ). Figure 2 (below) shows the employability attributes with which respondents most identified. Whilst this data is not necessarily representative, it has provided qualitative comments that are discussed below.

\section{2) Conversation Club: feedback from facilitators}

Conversation Club Facilitators are not formally surveyed, so feedback was requested by an e-mail to recent facilitators, asking them to reflect on whether, and how, being a facilitator had prepared them for employment. 
In addition to this, one student facilitator produced a case study reflecting on her development in the role. Extracts have been included in the discussion below and the author is credited as a co-author of this paper.

\section{3) Institutional data}

BU has a strong Student Development Award (SDA), which involves collecting points for undertaking different extracurricular activities. Being a PAL Leader or Conversation Club Facilitator both carry a high proportion of the points-tariff for the award. Students also submit reflective writing, evidencing how extracurricular activities have developed graduate attributes. Examples of reflective writing have been analysed as a source of qualitative data that describes how peer learning experiences have contributed to the development of specific attributes.

We have also used data from work placements to identify which employability attributes the employers of our peer learning leaders value. We identified 31 job descriptions for the student work placements and analysed these to identify examples of the specific attributes required by employers.

Figure 2 shows the proportion of job descriptions identifying attributes that BU peer leaders commonly recognised as having developed. It could be argued that this is selfselecting, in that job descriptions were scanned for mention of the attributes our leaders had identified. The sample is certainly too small to be representative; alongside the literature, however, this analysis has helped us to decide which attributes to discuss in this paper. 
Figure 2. Attributes peer leaders identified as having developed most compared to attributes identified in placement job descriptions.

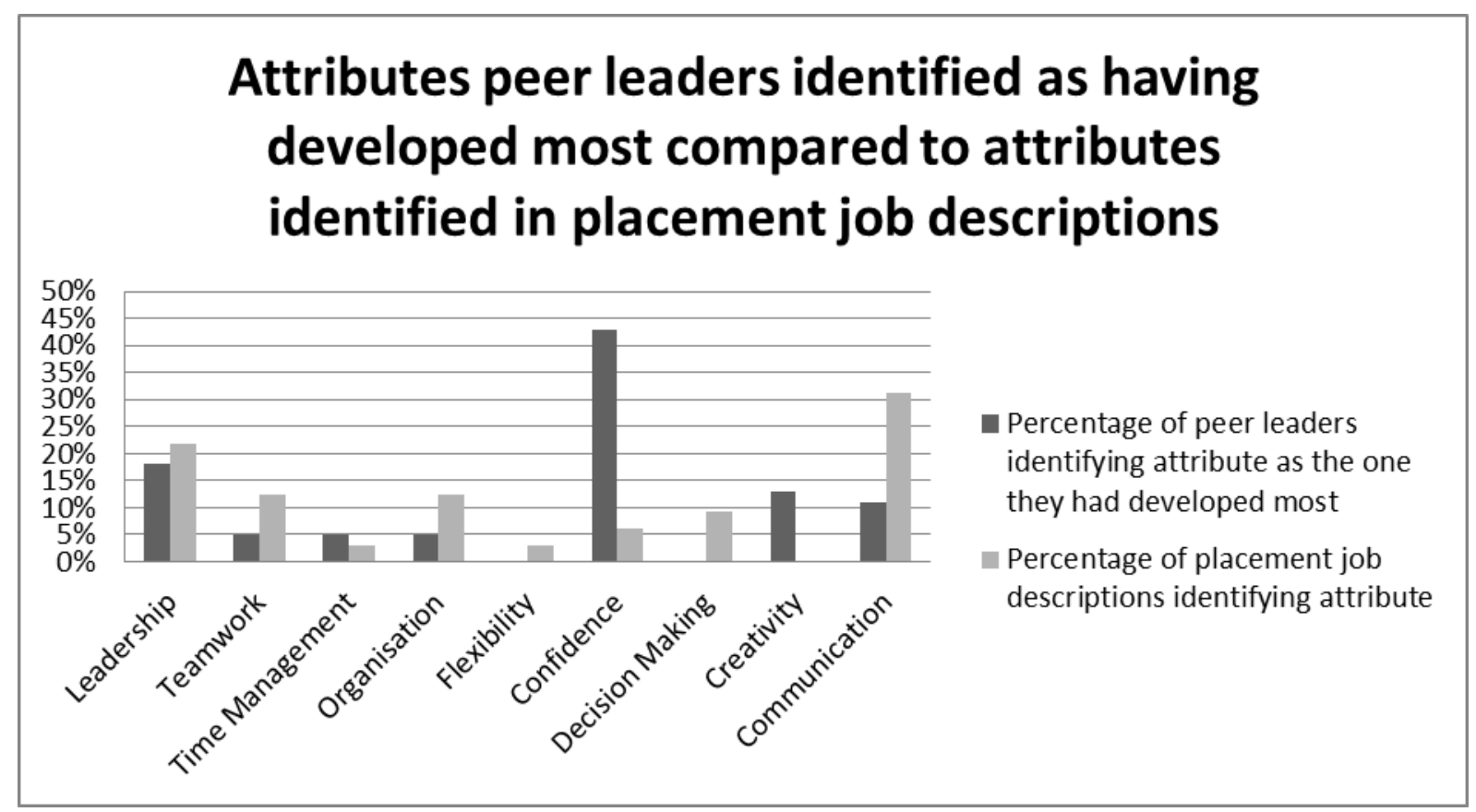

\section{Discussion: do PAL and Conversation Clubs develop employability?}

In this section, we discuss the development of selected employability attributes by peer learning leaders. Leadership, organisation and time management, communication, cultural awareness, and confidence are discussed with reference to their importance in employability.

Two sources from the literature have been particularly influential in selecting these categories: 'The Bloomberg Recruiter Report' (Bloomberg Business, 2015) and Hinchliffe and Jolly's 'Graduate Identity and Employability' (2011). Both surveyed employers to offer insight into which graduate attributes are valued. The Bloomberg Recruiter Report refers specifically to MBAs (and is therefore potentially discipline biased); what is interesting is that it asked employers to categorise how common and how desirable attributes were in recruits. We found the 'less common, more desired' category helpful for identifying attributes that our students may have limited opportunities to develop and that are highly valued by employers. 


\section{Leadership}

$22 \%$ of the placement job descriptions we reviewed identified leadership as important (Figure 2) and identified a range of activities such as leading events or motivating teams. Bloomberg identifies leadership as 'less common, more desired' (Bloomberg Business, 2015), suggesting that opportunities to develop leadership may be limited. There is an obvious need for leadership in business management roles where employers expect graduate skills to include:

An additional focus on empowerment, delegation, change management, building teams, and motivating others (Riebe and Jackson, 2014, p.320)

However, it is important to distinguish that leadership attributes are valuable in a broader sense than those required of business management roles. Kelley's concept of independent 'followership' highlights that some attributes commonly ascribed to leaders, such as critical thinking and acting independently, are important attributes for any effective team member to demonstrate (Kelley, 1988).

$77 \%$ of respondents to our PAL leader survey considered that their 'Leadership/ teamwork skills' had developed (Figure 1) and $17.9 \%$ selected it as the main attribute that they gained through PAL (Figure 2). Qualitative comments from peer leaders suggest that peer learning roles offer leadership experience that students may have limited opportunities to practice. Comments tended to focus on facilitative and democratic facets of leadership style rather than authoritarian or managerial approaches, for example:

It wasn't about managing them, talking at them or giving instructions; it was heavily reliant on a two-way relationship. (PAL Leader)

There are numerous examples of peer leaders identifying experiences relating to working with others and evidence of behaviours that enable this, such as: team working; cultural awareness (see below); and conflict resolution (Riebe and Jackson, 2014).

Similarly, peer leaders identified the coaching and mentoring aspects of the role as an effective leadership style. Some even suggested that they could apply coaching techniques to their own development: 
I will be able to see in myself when I need to improve and personally be able to reflect on it and change'. (PAL Leader)

This suggests a high level of reflective ability - applying the experience of leading others through coaching and mentoring techniques to their own independent personal development.

The conversation club case study provided insight into how experiencing being a leader regularly over time helped to develop confidence and interpersonal skills as facets of leadership (Mahoney et al., 2003):

The consistent participation throughout my degree increased my confidence and interpersonal skills which enabled me to transfer this confidence onto the academic level. (Katharina Hendrickx, Conversation Club Facilitator)

Qualitative comments provided numerous examples of leaders gaining confidence in the role of a leader over time and highlights the opportunities that peer learning provides for leaders to develop their learning through practice and reflection. Our data also suggests that peer leaders are able to utilise their experiences to gain further employment in leadership roles. For example, two facilitators secured work as a summer school leader in the United States and as an activity leader for a local language school, both citing experience as a peer leader as significant.

\section{Time management/organisation}

Hinchliffe and Jolly identified that employers expect graduates to be able to "plan and manage their time' as soon as they are appointed (2011, p.571). Time management and organisation were identified in $16 \%$ of the placement job descriptions reviewed. There is evidence that our peer learning leaders identify with developing these skills. Unfortunately, we're not able to disaggregate organisation from presentation skills in the PAL Leader survey. Interestingly though, the strongest response to another survey question, What advice would you offer future PAL Leaders?, is consistently to 'plan and prepare', suggesting that leaders have learnt this through experience (Ford and Thackeray, 2014). 10\% of respondents to our additional survey identified time management or organisation as the main attribute they had developed (Figure 2). 
Qualitative comments included reflection on planning sessions, making time to spend with students, and organising sessions that were diverse and creative enough to suit everyone, especially in the context of increased commitments for their own studies. Comments relating to organisation and time management again highlighted that employability attributes can overlap. For example, PAL Leaders working in pairs reflected that collaborative working required planning and one respondent remarked that their presentation skills have improved through learning the importance of timing. Conversation Club Facilitators are expected to schedule and book rooms for their sessions and communicate this to their students, whilst managing their own studies. This case study extract highlights the development opportunities provided by schemes that require students to plan and organise their own sessions:

I quickly discovered that there was far more required of me than I initially thought and that I had to use more than just my language skills. I had to plan each lesson carefully in advance and predict the timings of each exercise in order to have enough material for each session. This challenged me to get organized and manage my time efficiently. (Katharina Hendrickx, Conversation Club Facilitator)

\section{Communication}

There is strong evidence that employers value communication. Hinchcliffe and Jolly (2011, p.575) identified 'interpersonal skills' and 'written communication skills' as the categories ranked highest by employers and The Bloomberg Report found communication to be a highly desired attribute and less common in graduates (Bloomberg Business, 2015). $32.1 \%$ of the placement job descriptions we reviewed sought 'excellent' communication skills. The job descriptions illustrated that 'communication skills' can be expressed as a number of related themes. Some focused on people skills, a larger proportion emphasised 'tailoring' communications to different groups, and others specified listening and presenting attributes. $78.7 \%$ of PAL Leader survey respondents considered that the role had developed their communication skills and $10.7 \%$ selected it as the attribute that had most developed. It is perhaps unsurprising that PAL Leaders identify strongly with communication skills, as training for the role carries a strong emphasis on listening and questioning and this is a key part of the role. 
Qualitative data from both peer learning schemes offers insight into how leaders develop their interpersonal communication and a number of themes emerge. Some, for example, referred to sharing relatable experiences with others:

...making the support and guidance relatable is important to pique the student's interest (PAL Leader)

This demonstrates understanding that the subjective experience of the audience differs from their own and suggests an ability to flex their behaviour to achieve the best outcome. 'Behavioural flexibility is an integral component of communication competence' (Martin, 2003, p.3) and it appears that peer learning offers valuable opportunities to practice. This relates to employer requirements to 'tailor' communications and may also be an important aspect of cultural diversity:

It helped me understand my language better because I had to teach it considering you're speaking to an audience whose language doesn't function in the same way. (Conversation Club Facilitator)

Another theme relates to delivering communication: partly in terms of organising the content and partly in terms of engaging learners. Mehrabian's research (1981) into the verbal and non-verbal elements of communication has become widely accepted and comments show that peer learning leaders recognise the importance of words, body language, and tone in effective communication:

Speaking in front of people, listening to others, being aware of posture etc. when in front of people - all developed my communication skills. (PAL Leader)

Some respondents also recognised that they had practised listening, explaining and clarifying information:

I had to be clear and concise when speaking in-front of the group...listening effectively to the group to understand any problems or issues that they needed addressing. (PAL Leader) 
Peer leaders clearly recognised the importance of communication in the workplace. For example, one participant expressed how important it would be 'to communicate with fellow colleagues and clients'.

\section{Cultural awareness}

The ability to work with diverse clients and customers in a global economy is a growing business driver (Hinchliffe and Jolly, 2011, p.574). This clearly links to the internationalisation theme in higher education and student diversity is an important resource that can be harnessed to develop global citizenship (Caruana, 2014). SuárezOrozco and Sattin (2007) suggest that Global citizens:

Need the cultural sophistication to empathise with their peers who will likely be of different racial, religious, linguistic and social origins (Suárez-Orozco and Sattin, 2007, p.61).

Riebe and Jackson (2014) identify cultural and diversity awareness alongside conflict resolution as important behaviours when working with others, and there is evidence that peer learning can provide valuable opportunities to practice:

...many of the students participating in the Language Conversation Clubs were from across the world which oftentimes leads to cultural misunderstandings. I found myself more than once in the role of the mediator, listening to both sides and making sure this would not interfere with the learning process... (Katharina Hendrickx, Conversation Club Facilitator.)

Qualitative data suggests that some peer leaders developed cultural awareness through their roles. Leaders seemed to mostly attribute gaining cultural awareness through speaking to students about differences between the UK and other countries, and through establishing a safe, inclusive environment where they could talk about whatever they wanted. From our analysis, the development of cultural awareness appears to be closely inter-related with communication.

'Voluntary social segregation' among student groups is a known barrier to cultural exchange (Caruana, 2014, p.86). Our data suggests that peer learning can create safe 
learning environments that foster cross-cultural exchange and enable students to benefit from international mobility:

...there's actually not much chance for me to make friends with British students. Thus, for me, the conversation club is not only a class to gain experience of language teaching, but also a chance to make friends, and understand British culture through personal conversation. (Conversation Club Facilitator.)

We found evidence that peer learning provides opportunities for both international and domestic students to learn from experiencing other cultures. The Conversation Club case study offers deeper insight into the process by which peer learning can achieve cultural exchange (Eccles and Barber, 1999):

I saw myself as a role model who encourages and supports introverted students and enables an open-minded and non-judgemental space for debate and exchange between students. This greatly improved my emotional intelligence as well as ethnical sensitivity which are important skills in order to build trust and a friendly learning environment, giving every student an equal opportunity to participate in the learning process. (Katharina Hendrickx, Conversation Club Facilitator.

This example suggests that peer leaders are able to employ a number of behaviours (such as social intelligence and conflict resolution) to create a safe environment for cultural exchange, which in turn develops cultural awareness.

\section{Confidence}

It is challenging to justify our inclusion of 'confidence' as an employability attribute. It does not feature in any of the lists of employability skills we referred to and was rarely mentioned in placement job descriptions. Confidence is not explicitly mentioned in the CBI/NUS student guide to employability 'Working Towards Your Future' (CBI and NUS, 2011), however, a quote from a recent graduate in a CBI focus group offers some insight into our rationale for discussing confidence: 
When I went to my interview they were hardly asking me about my degree.

They were asking me about confidence, how I react, and leadership skills.

That's what gets you the job! (CBI and Universities UK, 2009, p.18.)

On one level, confidence can represent a level of attainment relating to other attributes (for example 'confident communication'). There also appears to be an aspect of selfconfidence, possibly relating to the concept of self-efficacy and an overall positive selfbelief in being 'up-to-the-job'.

Across all of our data, confidence is the attribute that our peer leaders most identify with developing in their role. $84.1 \%$ of PAL Leaders stated that they had developed confidence, with $42.9 \%$ citing it as the attribute they had developed most. Qualitative comments suggest that confidence is seen as an overarching attribute:

Being a PAL Leader has given me so many skills that I was able to speak about in interviews, (all of the options!!) however, confidence I think is the overriding factor for me. (PAL Leader.)

Peer learning leaders identified building confidence from a number of aspects of the role, including: receiving positive feedback from the students; reflecting on successful sessions; and from leading the group when they were not necessarily an expert in the subject. For some this had a significant impact in overcoming previous negative employment experiences.

Overcoming nerves is a common theme in the data. Leaders often admitted to being nervous before they ran their first session and then growing in confidence as time passed:

I have to say that this experience has increased my self-confidence: as I am very shy and usually not keen to speak in public, I found that after the first few lesson I felt much better already. (Conversation Club Facilitator.)

A number of respondents reflected how they had been able to transfer the confidence to other contexts, for example: when presenting to groups; 'speaking-out' in seminar groups; applications, assessment centres and interviews for placements or jobs; and with career 
direction. Peer leaders also mentioned actively seeking opportunities to develop their confidence to address self-perceived development needs.

It was the first time living on my own and in a foreign country. I was quite shy and felt lost at university. Thus, it was difficult to make friends and I lacked a feeling of belonging...I applied for a few extracurricular activities including the Language Conversation Clubs in the hope to meet new people and engage in new experiences. (Katharina Hendrickx, Conversation Club Facilitator.)

As well as providing a social learning environment for participants, there is some evidence that peer learning can provide a safe space for leaders to practise their skills:

The more I gained the friendship of the students, the easier it was for me to teach. I developed a great deal of self-confidence and public speaking skills through the weekly practice, which also benefitted me in academic presentations. (Katharina Hendrickx, Conversation Club Facilitator.)

In a sense this is co-created. Peer leaders use their facilitation skills to foster the social learning environment which, when successful, enables the peer leader to gain confidence through observing the positive outcomes of their behaviour. Feedback from participants can validate and situate the peer learning leader's self-assessment. Again, there is evidence that successful peer leaders gain the confidence to apply their skills in other settings and are able to use their experience to obtain further opportunities (Dickinson, 2000), for example:

I have been able to use the transferable skills to obtain work placements in South Africa and the USA and finish my degree successfully with a scholarship offer for my Master. I believe it helped me to close the skills gap many graduates are confronted with when graduating. (Katharina Hendrickx, Conversation Club Facilitator.) 


\section{Conclusions}

We conclude that peer learning roles can help leaders to develop leadership, organisation and time management, communication, cultural and diversity awareness, and above all, confidence within their roles.

Qualitative comments have been particularly useful in identifying how peer learning leaders develop these attributes through their experience of practising in the role. A number of comments have identified that this is a sustained development over time, and there are numerous examples of peer leaders reflecting on initial lack of understanding or nervousness, to become confident practitioners following positive feedback from their groups. There are also numerous examples of peer leaders being able to transfer attributes to other contexts, both academically and in employment.

The concept of confidence cuts across all attributes. Peer leaders report building confidence through practising specific attributes and also report a broader self-confidence that comes from overall reflection on their development in the role. Some peer leaders have actively sought leadership activities to address self-perceived development needs (for example, shyness). This independent personal and professional development indicates sophisticated self-reflection. It is reassuring that some peer leaders are independently aware of their own development needs and that peer learning provides opportunities to address them.

Definitions of employability are 'complex and multi-faceted' (Edwards, 2014, p.229). Our selection of specific attributes could be argued to be subjective and we therefore suggest that further work would benefit from exploring and mapping to accepted models of employability.

Whilst we have observed employability development in peer leaders, our analysis does not offer insight into the effectiveness of peer learning compared to other forms of student development. This distinction is hard to prove and further research may benefit from objective measurement, for example, using psychometric testing. As we found confidence to be a significant factor, there may also be some merit in exploring established psychological measures of confidence or self-efficacy, and this is consistent with emerging research from other peer learning schemes. 
We acknowledge that relatively low response rates are a limitation of this study. We attribute this to a number of factors, including: timing, survey fatigue, and institutional limitations on promoting surveys. Selection bias is also a potential limitation. For example, the students who volunteer to be Conversation Club Facilitators could be argued to already be culturally aware as they have chosen to study in a foreign culture, so we are cautious about making any claims about wider groups. In this context, it is important to acknowledge that not all peer learning leaders will have had a positive experience. Further studies should seek to identify how negative experiences of peer learning leadership may affect employability, as well as how best to support all leaders through training, session observations, debriefs, and reflective practice.

Our study has highlighted local variation in evaluating peer learning schemes. We reflect that there is potentially value in developing standardised measures for peer learning schemes to enable data to be compared across different peer learning initiatives and institutions.

Student portfolios are acknowledged to be an effective form of assessing employability skills (Riebe and Jackson, 2014) and we found reflective writing from Student Development Award portfolios to be a useful source of evaluation data. We reflect that it would be beneficial to investigate embedding the use of reflective portfolios in peer learning schemes. Riebe and Jackson (2014) highlight the use of rubrics to assess employability portfolios and this could provide both an objective measure of student development, as well as scaffolding opportunities for peer leaders to reflect on their development.

There is also potential to use institutional data to investigate outcomes. Destination of Leavers of Higher Education (DLHE) data could provide evidence of correlation between engagement with peer learning and employment success. Whilst this would be prone to achievement bias, it could be validated with qualitative data from alumni and employers.

Work experience is only valuable if it can be translated and transferred into other contexts, requiring strong interpersonal skills and capacity for reflective thinking. We conclude that student-led peer learning provides opportunities to develop employability and a useful focus will be to investigate and enhance ways to encourage participants to reflect on their experiences and integrate them with their graduate identity. 


\section{References}

Bloomberg Business (2015) The Bloomberg Recruiter Report: job skills companies want but can't get. New York: Bloomberg. Available at:

http://www.bloomberg.com/graphics/2015-job-skills-report/ (Accessed: 17 August 2015 2015).

Bournemouth University (2014) Peer Assisted Learning (PAL): an overview. Bournemouth: Bournemouth University. Available at: http://www.bournemouth.ac.uk/library/guestvisitor/pal.html (Accessed: 10 August 2015).

Capstick, S. (2004) Benefits and shortcomings of Peer Assisted Learning (PAL) in higher education: an appraisal by students. Working copy produced for the Peer Assisted Learning conference, January 2004. Bournemouth: Bournemouth University [Working paper]. Available at:

https://www1.bournemouth.ac.uk/sites/default/files/asset/document/stuartcapstick.pdf (Accessed: 14 November 2015).

Caruana, V. (2014) 'Re-thinking global citizenship in higher education: from cosmopolitanism and international mobility to cosmopolitanisation, resilience and resilient thinking', Higher Education Quarterly, 68(1), pp. 85-104.

CBI and NUS (2011) Working towards your future: making the most of your time in higher education. London: CBI. Available at:

http://www.nus.org.uk/Global/CBI NUS Employability\%20report May\%202011.pdf (Accessed: 15 August 2015).

CBI and Universities UK (2009) Future fit: preparing graduates for the world of work. London: CBI. Available at: http://www.cbi.org.uk/media/1121435/cbi uuk future fit.pdf (Accessed: 15 August 2015). 
Dawson, P., van der Meer, J., Skalicky, J. and Cowley, K. (2014) 'On the effectiveness of supplemental instruction: a systematic review of supplemental instruction and peerassisted study sessions literature between 2001 and 2010', Review of Educational Research, 84(4), pp. 609-639.

Deeley, S.J. (2014) 'Summative co-assessment: a deep learning approach to enhancing employability skills and attributes', Active Learning in Higher Education, 15(1), pp. $39-51$.

Dickinson, M. (2000) 'An Analysis of the accreditation of transferable skills in extra curricular activities within higher education', Assessment \& Evaluation in Higher Education, 25(1), pp. 61-70.

Eccles, J.S. and Barber, B.L. (1999) 'Student council, volunteering, basketball, or marching band: what kind of extracurricular involvement matters?', Journal of Adolescent Research, 14(1), pp. 10-43.

Edwards, M. (2014) 'The impact of placements on students' self-efficacy', Higher Education, Skills \& Work-based Learning, 4(3), pp. 228.

Ford, N. and Thackeray, C. (2014) Evaluation of the Peer Assisted Learning (PAL) Scheme at Bournemouth University 2013/14. Bournemouth: Bournemouth University. Available at:

https://www1.bournemouth.ac.uk/sites/default/files/asset/document/pal-evaluation2013-14.pdf (Accessed: 17 August 2015).

Hager, P. and Hodkinson, P. (2009) 'Moving beyond the metaphor of transfer of learning', British Educational Research Journal, 35(4), pp. 619-638.

Harvey, L. (2003) Transitions from higher education to work. Sheffield: Centre for Research and Evaluation, Sheffield Hallam University. Available at: http://www.qualityresearchinternational.com/esecttools/esectpubs/harveytransitions. pdf (Accessed: 17 August 2015). 
Higher Education Academy (2014) Internationalising higher education framework. York:

Higher Education Academy. Available at:

https://www.heacademy.ac.uk/sites/default/files/resources/InternationalisingHEfram eworkFinal.pdf (Accessed: 17 June 2015).

Higher Education Academy (2015) Employability. York: Higher Education Academy.

Available at: https://www.heacademy.ac.uk/workstreamsresearch/themes/employability (Accessed: 17 June 2015).

Hinchliffe, G.W. and Jolly, A. (2011) 'Graduate identity and employability', British Educational Research Journal, 37(4), pp. 563-584.

Kelley, R.E. (1988) 'In praise of followers', Harvard Business Review, 66(6), pp. 142-148.

Lowden, K., Hall, S., Elliot, D. and Lewin, J. (2011) Employers' perceptions of the employability skills of new graduates: research commissioned by the Edge Foundation. Glasgow: University of Glasgow SCRE Centre and Edge Foundation. Available at: http://www.edge.co.uk/media/63412/employability_skills_as_pdf__final_online_version.pdf (Accessed: 14 November 2015).

Mahoney, J.L., Cairns, B.D. and Farmer, T.W. (2003) 'Promoting interpersonal competence and educational success through extracurricular activity participation', Journal of Educational Psychology, 95(2), pp. 409-418.

Martin, P.W. (2003) 'Key aspects of teaching and learning in arts, humanities and social sciences', in Fry, H., Ketteridge, S. and Marshall, S. (eds.) A handbook for teaching and learning in higher education: enhancing academic practice. $2^{\text {nd }}$ edn. New York/London: Routledge, pp. 301-323.

Mehrabian, A. (1981) Silent messages: implicit communication of emotions and attitudes. $2^{\text {nd }}$ edn. Belmont, CA: Wadsworth Publishing Co Inc. 
Pegg, A., Waldock, J., Hendy-Isaac, S. and Lawton, R. (2012) Pedagogy for employability. York: Higher Education Academy. Available at:

https://www.heacademy.ac.uk/sites/default/files/pedagogy for employability updat e 2012.pdf (Accessed: 22 June 2015).

Riebe, L. and Jackson, D. (2014) 'The use of rubrics in benchmarking and assessing employability skills', Journal of Management Education, 38(3), pp. 319-344.

Saunders, D. and Gibbon, M. (1998) 'Peer tutoring and peer-assisted student support: five models within a new University', Mentoring \& Tutoring: Partnership in Learning, 5(3), pp. 3-13 [Online]. Available: Routledge. Available at:

http://www.tandfonline.com/doi/abs/10.1080/0968465980050301 ?journalCode=cme

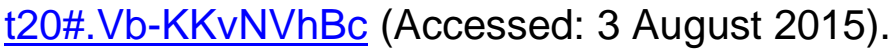

Stout, M.L. and McDaniel, A.J. (2006) 'Benefits to Supplemental Instruction Leaders', New Directions for Teaching and Learning, no. 106, Summer 2006, Wiley Periodicals Inc., pp. 55-62 [Online]. Available at:

http://supportservices.ufs.ac.za/dl/userfiles/Documents/00001/975 eng.pdf (Accessed: 3 August 2015).

Suárez -Orozco, M.M. and Sattin, C. (2007) 'Wanted: global citizens', Educational Leadership, 64(7), pp. 58-62.

\section{Author details}

Neil Ford is Academic Liaison Development Manager in Library and Learning Support at Bournemouth University and coordinates their Peer Assisted Learning programme. Neil has developed a number of student co-creation projects and is interested in working with students as partners in learning.

Charlotte Thackeray is Peer Learning Officer at Bournemouth University and centrally supports over 300 Leaders and 50 academics at the institution. She shares good practice with other institutions in the UK and develops excellent peer learning opportunities at BU. 
Paul Barnes is Language Learning Manager and EAP Tutor at Bournemouth University and his main interest has always been using technology in language learning. Paul is a keen advocate of using students to help other students.

Katharina Hendrickx has a BA in English and is currently studying her MA in Literary Media at Bournemouth University. Katharina has been teaching German at BU for three years and is passionate to learn more about different cultures and languages. 